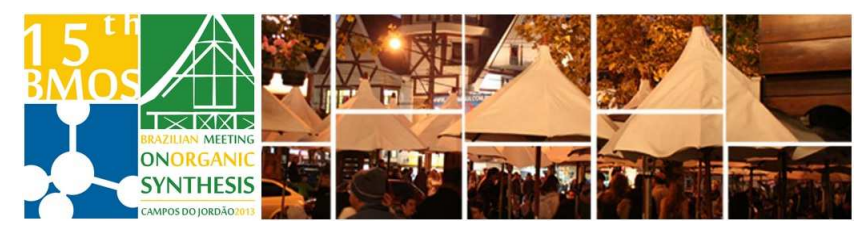

\title{
Glyco-Porphyrins and -Phthalocyanines for Cancer Photodynamic Therapy
}

\section{Patrícia M. R. Pereira, ${ }^{a, b}$ Leandro M. O. Lourenço, ${ }^{a}$ Mafalda A. F. Bispo, ${ }^{a, b}$ Sandrina Silva, ${ }^{a}$ José A. S. Cavaleiro, ${ }^{a}$ Carlos A. F. Ribeiro, ${ }^{b}$ Rosa Fernandes, ${ }^{b}$ João P. C. Tomé $^{\mathrm{a}^{\star}}$}

${ }^{a}$ QOPNA and Department of Chemistry, University of Aveiro, 3810-193 Aveiro, Portugal.

${ }^{b}$ LPET, IBILI and Faculty of Medicine, University of Coimbra, 3000-548 Coimbra, Portugal

*e-mail corresponding author: jtome@ua.pt

Keywords: (Glyco)Porphyrins, Cancer, Photodynamic therapy

\section{INTRODUCTION}

Porphyrins (Pors) and carbohydrates $(\mathrm{CH})$ are two families of natural compounds those are vital to our life. From the combination of both groups, many glyco-porphyrinoids have been synthesized and studied as photosensitizers (PSs) in cancer photodynamic therapy (PDT) with extremely success. ${ }^{1}$ PDT combines a PS, visible light at a specific wavelength, and molecular oxygen to produce cytotoxic reactive oxygen species (ROS) to kill cancer cells. ${ }^{2}$ In this communication, it will be highlighted some of our recent works, presenting the used synthetic strategies and some of the obtained photo-physical, -chemical and-biological results in the indicated field. ${ }^{3,4,5}$

\section{RESULTS AND DISCUSSION}

Our group has chemically modified the core of the porphyrinoids (porphyrins, chlorins and phthalocyanines; Figure 1) with galactodendritic units $^{2}$ and cyclodextrins (CDs) ${ }^{3}$.
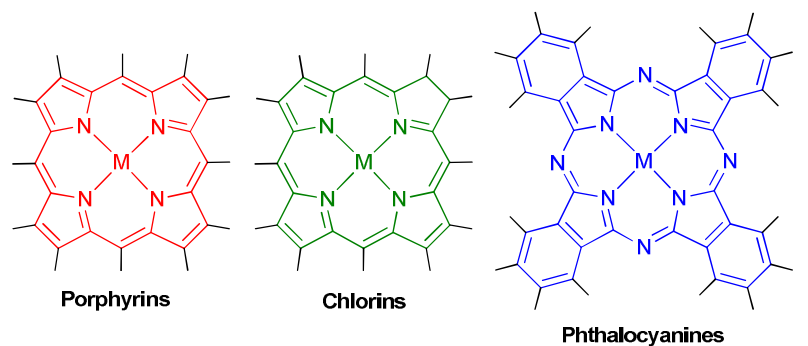

Figure 1. Porphyrin, chlorin and phthalocyanine structures.

The obtained conjugates have demonstrated outstanding photo-physical and -chemical properties $^{2,3}$ being water soluble, fluorescents, efficient singlet oxygen generators, photo-stable and able to interact with human serum albumin. The promising photo-physical data of the conjugates have prompted us to validate them as PSs against bladder cancer cells (UM-UC-3 and HT-1376). Studies of cellular uptake, induction of phototoxicity, apoptosis and ROS production were performed and the results show them as promising photodynamic agents for the treatment of bladder cancer (Figure 2).
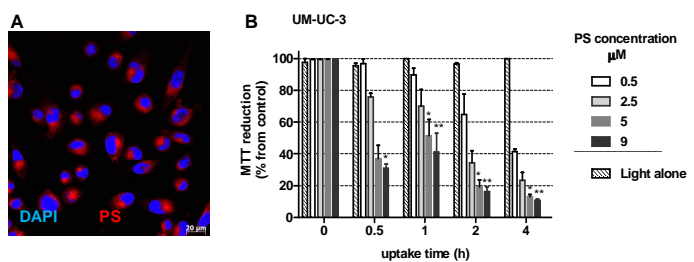

C

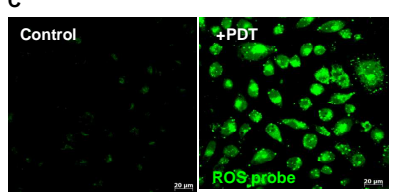

Control
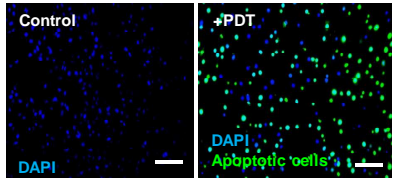

Figure 2. Uptake (A), phototoxicity (B), ROS production (C) and apoptosis (D) after PDT with our conjugates.

\section{CONCLUSION}

The in vitro results have demonstrated that our conjugates exhibit excellent biophysics-chemical properties and prompt us to envisage them as novel anticancer drug candidates for bladder cancer treatment, which is the fifth most common type of cancer with the highest rate of recurrence.

\section{ACKNOWLEDGEMENTS}

Thanks are due to the Universities of Aveiro and Coimbra, FCT (Portugal) and FEDER for funding the projects PTDC/QUI/65228/2006 and PTDC/CTM/101538/2008; and to the European Commission for the Marie Curie Initial Training Networks FP7-PEOPLE-2012-ITN/316975.

\section{REFERENCES}

${ }^{1}$ Cavaleiro, J.A.S.; Faustino, M.A.F.; Tome, J.P.C., Carbohydrate Chemistry, The Royal Society of Chemistry, 2009, 35, 199.

${ }^{2}$ Silva, S.; Pereira, P.M.R.; Silva, P.; Almeida Paz, F.A.; Faustino, M.A.F.; Cavaleiro, J.A.S.; Tomé, J.P.C.; Chem. Commun. 2012, $48,3608$.

${ }^{3}$ Lourenço, L.M.O.; Pereira, P.M.R.; Maciel, E., Domingues, M.R.M.; Fernandes, R.; Neves, M.G.P.M.S., Cavaleiro, J.A.S.;

Tomé, J.P.C. submitted, 2013.

${ }^{4}$ Pereira, P.M.R.; Silva, S.; Cavaleiro, J.A.S.; Ribeiro, C.A.F.; Tomé, J.P.C.; Fernandes, R. under final preparation.

${ }_{5}$ Pereira, P.M.R.; Carvalho, J.J.; Silva, S.; Cavaleiro, J.A.S.; Schneider, R.J.; Fernandes, R. and Tomé, J.P.C, under final preparation. 